\title{
Tornado Fatalities: An Environmental Perspective
}

\author{
AleXANDRA K. Anderson-Frey \\ Cooperative Institute for Mesoscale Meteorological Studies, University of Oklahoma, and NOAA/OAR/National Severe \\ Storms Laboratory, Norman, Oklahoma \\ HAROLD BROOKS \\ NOAA/National Severe Storms Laboratory and School of Meteorology, University of Oklahoma, Norman, Oklahoma
}

(Manuscript received 12 June 2019, in final form 15 October 2019)

\begin{abstract}
Deadly tornadoes are rare events, but that level of rarity varies with many factors. In this work, we summarize and update past research on tornado fatalities, and also discuss the environments of deadly tornadoes both from the perspective of proximity soundings (i.e., point-based) and self-organizing maps (i.e., two-dimensional). In our study of 16232 tornado events from 2003 to 2017, we find that deadly tornadoes are disproportionately likely to have high (E)F-scale ratings, to have right-moving supercell parent storm modes (deadly QLCS tornadoes are exceptionally rare and tend to result in only one death when they do occur), and to occur during the winter and spring. Warning skill is generally higher for deadly tornadoes than for nondeadly tornadoes: $87 \%$ of deadly tornadoes were warned in advance, and nearly $95 \%$ of tornado deaths occurred within an active warning. The same environments are warned well for both deadly and nondeadly tornadoes, but the deadly tornadoes tend to occur in environments that are less conducive to weaker (E)F0-1 tornadoes. We identify four prototypical deadly tornado scenarios using self-organizing maps, ranging from marginal environments resulting in relatively few fatalities to major deadly outbreak events. Overall results indicate that the most dangerous tornadoes (i.e., those with high numbers of deaths per deadly tornado) also generally occur in environments and under conditions in which warning skill is high. While, generally speaking, the correct storms are being warned, we include some recommendations for additional research and further improvement.
\end{abstract}

\section{Introduction}

Tornado deaths are a prime example of a rare event within a rare event: in the United States, between 1916 and 1953 , fewer than $5 \%$ of all days included at least one tornado death in the United States (Linehan 1957). Between March 1952 and 1973, only 3.4\% of tornadoes resulted in fatalities (Galway 1975), and the overall number of tornado deaths has since decreased, reflecting both a decrease in the number of deadly tornadoes and a decrease in the number of fatalities in the deadliest tornadoes (Brooks and Doswell 2002; Doswell et al. 1999; Simmons and Sutter 2005). In more recent years, however, a "leveling off" has been observed in fatality rates, attributed to increasing population exposure (Ashley and Strader 2016). In an analysis using wealth adjustment, Brooks and Doswell (2001) found that the

\footnotetext{
Corresponding author: Alexandra K. Anderson-Frey, akaf@ uw.edu
}

number of fatalities per million dollars damage was higher for major tornadoes between 1890 and 1953 than for major tornadoes between 1953 and 1999 (where 1953 marks the start of the National Weather Service watch/warning/awareness program). Between 2003 and 2017, the median (mean) number of tornado deaths per year was 41 (75), which is approximately in line with reported values over different periods of time in recent decades (Ashley 2007; Schoen and Ashley 2011).

These fatalities due to tornadoes are not evenly distributed, however: the majority of tornado deaths are attributable to only a small, particularly intense fraction of deadly tornadoes. In a study of 497 tornadoes between March 1952 and 1973, Galway (1975) noted that $235(47 \%)$ produced only one death, while just 26 tornadoes (5\%) accounted for 1180 deaths. In 1998, 95\% of the 131 tornado fatalities were associated with only 25 isolated storms (Schoen and Ashley 2011), and, while only $17.7 \%$ of all tornadoes that struck Alabama during the devastating 27 April 2011 outbreak were rated F4+, 
they were responsible for $89.5 \%$ of the deaths (Chiu et al. 2013). Some discussion has also ventured into the topic of subseasonal and seasonal prediction: Molina et al. (2018) found that both La Niña and El Niño phases of ENSO favor a higher fraction of deadly tornadoes, and that the comparatively low fraction of deadly tornadoes during ENSO-neutral phases is especially prominent over the Southeast.

The rarity of deadly tornadoes clearly does not diminish the exceptional impacts of events in which fatality rates are especially high; these outbreaks (i.e., sequences of multiple tornado events associated with the same mesosynoptic system) draw a great deal of attention. The tornado outbreak of 3 May 1999 was the deadliest in over 20 years, with 36 direct fatalities (Brooks and Doswell 2002; Brown et al. 2002). The first year since 1953 with more than 500 tornado fatalities recorded was 2011 (Simmons and Sutter 2012); during the 27 April 2011 outbreak, 338 fatalities were recorded in the states of Arkansas, Mississippi, Alabama, Tennessee, and Georgia alone (Chiu et al. 2013). The 22 May 2011 Joplin tornado was the single tornado that resulted in the most deaths (162) since modern record-keeping began in 1950 (Paul and Stimers 2014). Anderson-Frey et al. (2018) found that, between 2003 and 2017, 5\% of tornadoes that occurred during outbreaks resulted in at least one death, versus only $1 \%$ of tornadoes that occurred in isolation.

This work builds on the foundation laid by previous studies that have assessed the seasonality and regional distribution of tornado fatalities (e.g., Linehan 1957; Ashley 2007) and discussed these fatalities in terms of demographics (e.g., Chiu et al. 2013; Schumann et al. 2018), the particular risk faced by individuals in mobile homes (e.g., Daley et al. 2005; Strader and Ashley 2018; Liu et al. 2019), and long-term trends in impact magnitude (e.g., Strader et al. 2017a,b). We expand this past work in a new direction, however, by investigating tornado deaths from the perspective of the near-storm environment, using warning skill statistics to help clarify the distinction between scenarios resulting in tornado fatalities that could be reduced with better meteorological knowledge versus those that more likely require solutions outside of the physical-science domain. The use of self-organizing maps (SOMs; Anderson-Frey et al. 2017) provides a novel two-dimensional perspective on this environmental analysis.

\section{Dataset and methods}

\section{a. Tornado event database}

This paper employs a NOAA Storm Prediction Center dataset of 16232 tornado events occurring during the 15-yr period from 2003 to 2017. Smith et al. (2012) described the initial creation of this dataset, and the update of the data through 2017 was discussed and these data were applied in Anderson-Frey et al. (2019). This dataset filters county tornado segment data, keeping only the highest (E)F-scale value occurring within a given hour and $40 \mathrm{~km} \times 40 \mathrm{~km}$ area; as a result, any tornadoes occurring within the same $1 \mathrm{~h} \times 40 \mathrm{~km} \times 40 \mathrm{~km}$ are grouped together as a single event.

The spacing of the filter has been chosen to reflect the resolution of the mesoanalysis data from which the near-storm environmental data have been generated (Bothwell et al. 2002): each tornado event is matched with the nearest grid box within the mesoanalysis, from which sounding-derived parameters can be drawn. The background of these mesoanalyses comes from the Rapid Update Cycle model (RUC; Benjamin et al. 2004) for January 2003-April 2012 and the Rapid Refresh model (RAP; Benjamin et al. 2016) for later dates. The horizontal grid spacing of these model data is $40 \mathrm{~km}$, and the temporal data are hourly. Thompson et al. (2012) and Anderson-Frey et al. (2016) provided a more indepth discussion of the strengths and limitations of the dataset.

Also associated with each event-environment pair is warning verification information, so that the probability of detection (POD) can be calculated for any grouping of the tornado events. In the discussion that follows, POD will be defined as the fraction of all tornado events for which a warning was issued ahead of time (i.e., with positive lead time). Tornado fatality information and parent storm mode information are also provided for each event (Smith et al. 2012).

Tornadoes are most common in the Southeast, the Great Plains, the Midwest, and the northern plains, with some additional activity in the Northeast (Fig. 1a). Narrowing the focus to only deadly tornado events (i.e., those that resulted in at least one death) (Fig. 1b) shows that these deadly tornadoes have several maxima, most notably from northern Alabama through southern middle Tennessee, and in southwestern Missouri through central Arkansas. The plot of individual tornado deaths (Fig. 1c) highlights certain major events, such as the 2011 Joplin, Missouri, tornado, the 2013 tornadoes in central Oklahoma, and tornadoes that occurred during the 27 April 2011 tornado outbreak in the Southeast. Many deadly tornadoes, however, resulted in only one death, with just over half $(51 \%)$ resulting in more than one. Only $12 \%$ of these deadly tornadoes were responsible for more than half ( $53 \%$ ) of the deaths, with a mean (median) number of deaths per deadly tornado of only 3.5 (2). 

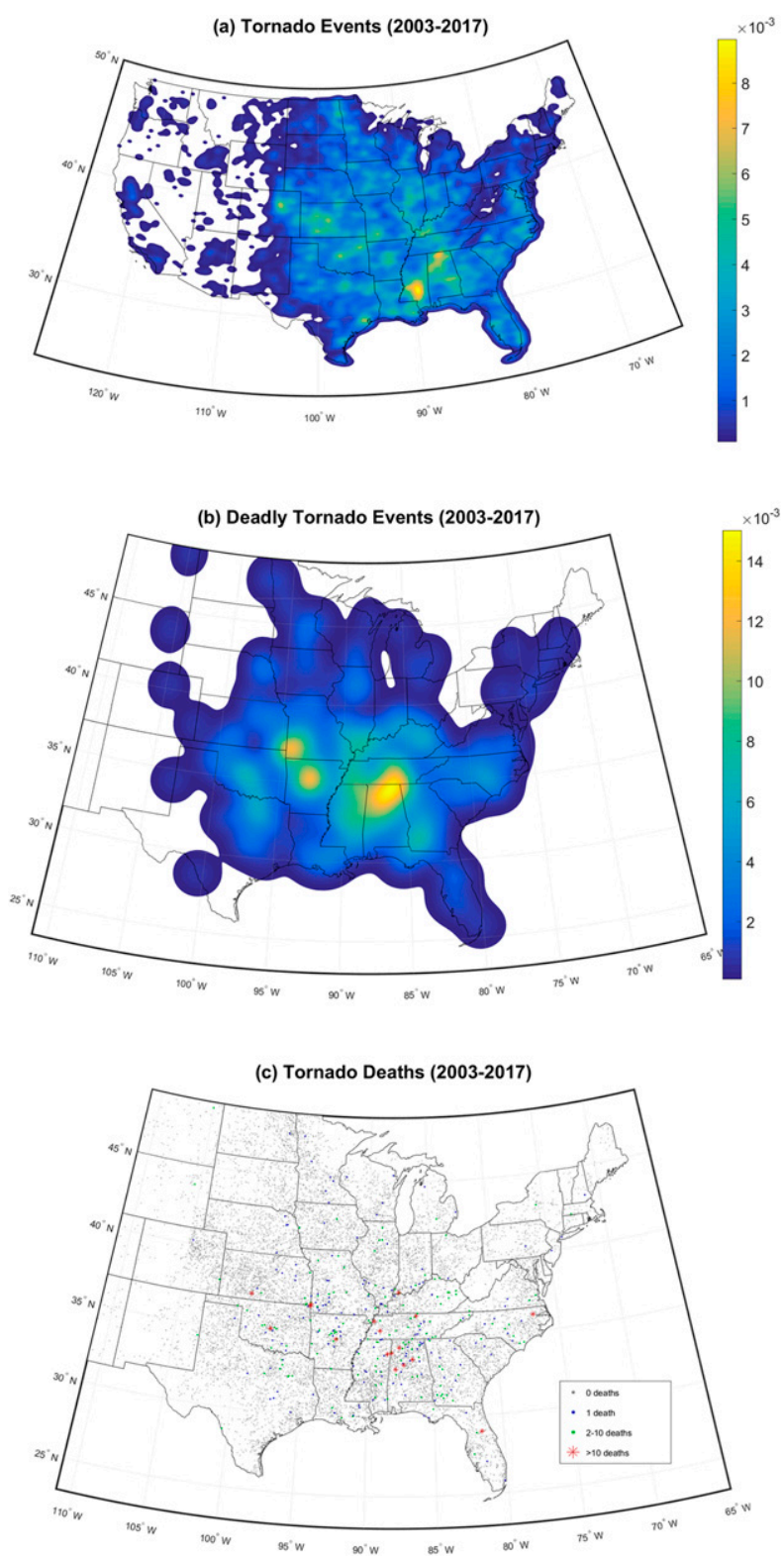

FIG. 1. Kernel density estimation (KDE) plots of (a) all tornado events and (b) deadly tornado events (i.e., tornado events resulting in at least one death). (c) Plot of tornado events by number of deaths. KDE bandwidths for (a) were $0.20^{\circ}$ (latitude) and $0.37^{\circ}$ (longitude), and for (b) were $0.72^{\circ}$ (latitude) and $0.86^{\circ}$ (longitude)

\section{b. Self-organizing maps}

A SOM is an artificial neural network (Kohonen 1982) that uses competitive learning to map input data onto a two-dimensional set of nodes; by treating the input data assigned to each node as clusters, a SOM can be used to objectively classify data [Nowotarski and Jensen (2013) provide a much more detailed overview]. When the input data are two-dimensional plots of environmental information [in our case, maps of the significant tornado parameter (STP) in a $480 \times 480 \mathrm{~km}^{2}$ region surrounding the location of the tornado; see section 5], each node can also be summarized by its mean two-dimensional map.

The SOM approach hence allows a user to cluster a set of maps around a set of objectively defined "prototypical" environments, and the statistics of each cluster (e.g., POD) can then be calculated and compared. The only user-defined parameter in a SOM is the number of nodes; based on a qualitative assessment similar to that depicted in Anderson-Frey et al. (2017; their Fig. 1), the SOM in section 5 will be constructed with $2 \times 2$ nodes, resulting in a total of four summary scenarios in which deadly tornadoes have occurred.

\section{Statistics of deadly tornadoes and tornado deaths}

\section{a. Intensity}

Tornado intensity, as measured by the (E)F-scale rating, is strongly connected to the number of deaths per tornado. Ashley (2007) found that, between 1985 and $2005, \mathrm{~F} 4+$ tornadoes were responsible for nearly twothirds of all tornado fatalities, and F2+ tornadoes were responsible for nearly all $(98.8 \%)$ tornado fatalities. Between 1950 and 2007 , the $1.2 \%$ of tornadoes rated $\mathrm{F} 4+$ accounted for $62 \%$ of the fatalities, while F0-1 tornadoes (which comprised $78 \%$ of all tornadoes) accounted for only $5 \%$ of fatalities (Simmons and Sutter 2011). EF5 tornadoes alone between 2000 and 2011 resulted in over a quarter (26\%) of tornado deaths (Paul and Stimers 2014).

Figure 2a is in line with these statistics: while (E)F0-1 tornadoes make up $86 \%$ of all tornadoes, they are responsible for a very small percentage of deadly tornadoes $(11.9 \%)$ and an even smaller percentage of tornado deaths $(3.9 \%)$. On average, only $0.3 \%$ of (E)F0-1 tornadoes are deadly, and even when a deadly (E)F0-1 tornado does occur, the mean (median) number of deaths associated with a deadly (E)F0-1 tornado is only 1.2 (1) (Table 1).

Tornadoes rated (E)F2-3 make up 12.7\% of all tornadoes, and they comprise a higher percentage of deadly tornadoes $(65.3 \%)$ and tornado deaths (45.3\%) (Fig. 2a). (E)F2-3 tornadoes result in at least one death $10.1 \%$ of the time, and the mean number of deaths associated with a deadly (E)F2-3 tornado is 2.4 (2) (Table 1).

Finally, while (E)F4+ tornadoes make up only $0.8 \%$ of all tornadoes, they are responsible for $22.8 \%$ of deadly tornadoes and $50.8 \%$ of tornado fatalities (Fig. 2a). The $59.8 \%$ of tornadoes rated (E)F4+ resulted in at least one death, and the mean (median) number of deaths associated with a deadly (E)F4+ tornado is 7.8 (3) (Table 1). Note that, even though the presence of an 

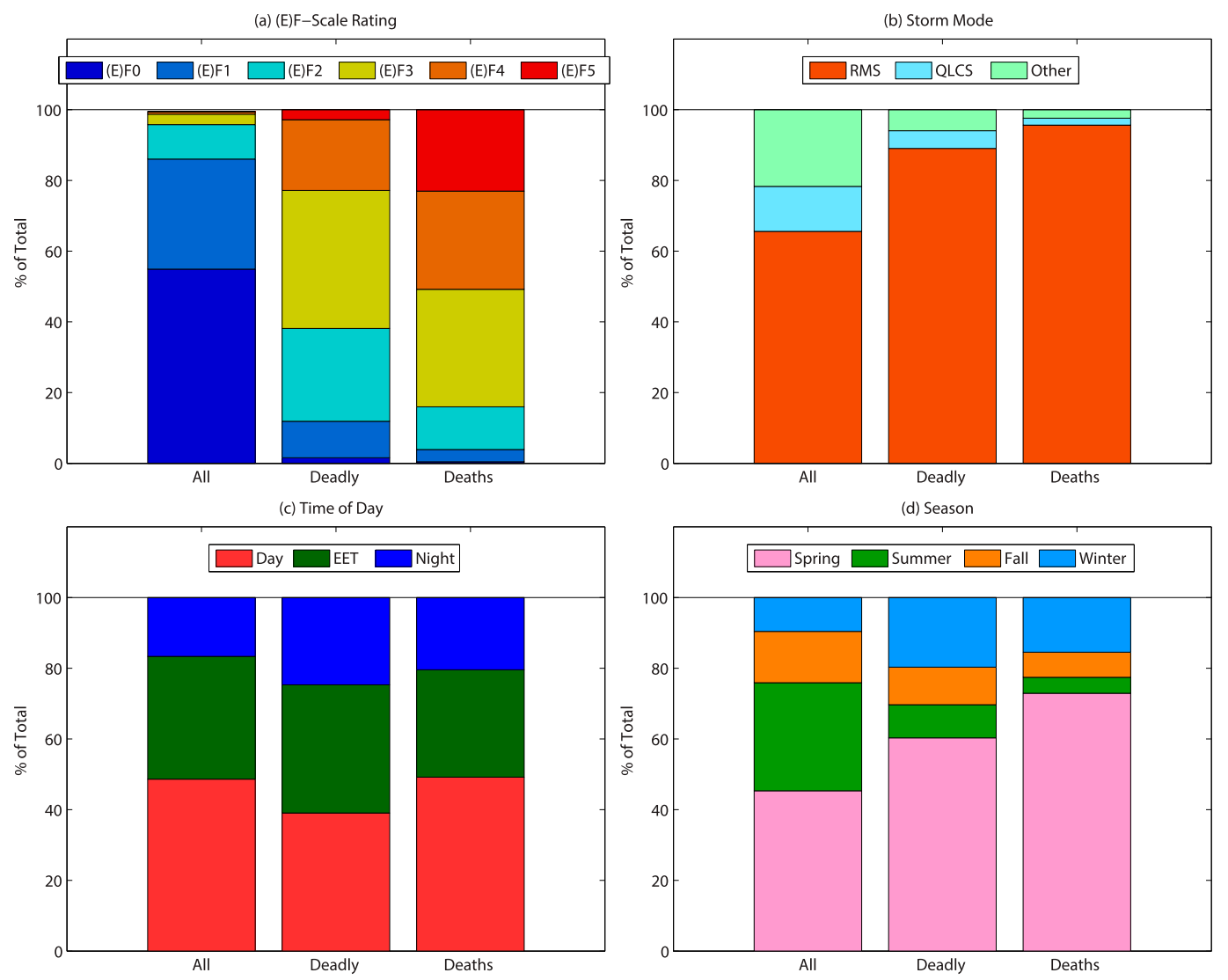

(e) Warning Skill

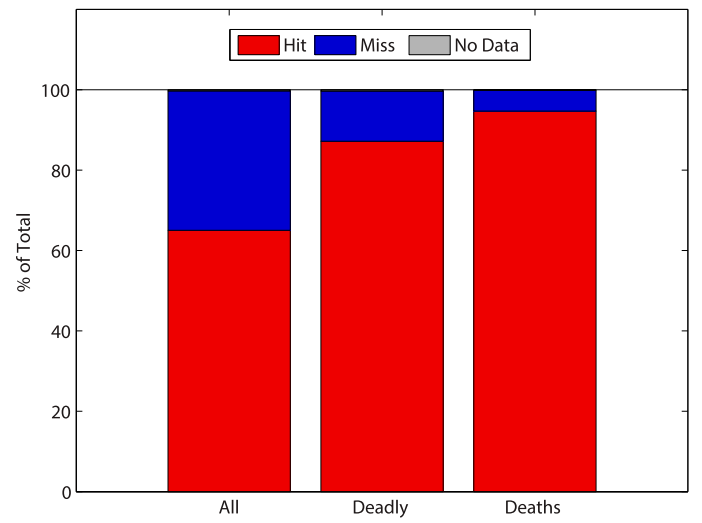

FIG. 2. Composition of 2003-17 tornado events, sorted by (a) (E)F-scale rating, (b) parent storm mode, (c) time of day, (d) season, and (e) warning skill. The leftmost bar in each plot is the distribution of these categories for the entire tornado event dataset, the center bar is the distribution of deadly tornado events (i.e., tornado events resulting in at least one death), and the rightmost bar is the distribution of tornado deaths. Note that storm mode shown in (b) can incorporate modes other than RMS or QLCS (see Smith et al. 2012). Time of day in (c) is defined as daytime (between local sunrise and two hours before local sunset), EET (between two hours before and two hours after local sunset), and nighttime (between two hours after local sunset and local sunrise). Season in (d) is defined meteorologically: spring is MAM, summer is JJA, fall is SON, and winter is DJF. The "no data" label for warning skill in (e) represents the $0.3 \%$ of events for which no warning data are available.

outlier event (with 157 deaths; the second-highest number of deaths in this data subset is 46) skews the mean, the median is still higher than that for deadly (E)F0-3 tornadoes.
Thus, more intense tornadoes are considerably more likely than weaker tornadoes to result in at least one death, and these deadly tornadoes are more likely to result in numerous fatalities. While $(\mathrm{E}) \mathrm{F} 4+$ tornadoes 
TABLE 1. For the subcategories described in section 3, the percent of that subcategory that resulted in at least one death, as well as the mean (median) number of deaths per deadly tornado.

\begin{tabular}{|c|c|c|c|c|}
\hline & & No. of tornadoes & Percent of deadly tornadoes (\%) & $\begin{array}{l}\text { Mean (median) No. of deaths } \\
\text { per deadly tornado }\end{array}$ \\
\hline All & & 16232 & 2.0 & $3.5(2)$ \\
\hline \multirow[t]{6}{*}{ (E)F scale } & $(\mathrm{E}) \mathrm{F} 0$ & 8912 & 0.1 & $1(1)$ \\
\hline & $(\mathrm{E}) \mathrm{F} 1$ & 5054 & 0.7 & $1.2(1)$ \\
\hline & $(\mathrm{E}) \mathrm{F} 2$ & 1580 & 5.4 & $1.6(1)$ \\
\hline & (E)F3 & 482 & 26.0 & $3.0(2)$ \\
\hline & $(\mathrm{E}) \mathrm{F} 4$ & 111 & 57.7 & $4.9(3)$ \\
\hline & (E)F5 & 11 & 81.8 & $28.8(14)$ \\
\hline \multirow[t]{2}{*}{ Storm mode } & RMS & 10648 & 2.7 & $3.8(2)$ \\
\hline & QLCS & 2064 & 0.8 & $1.4(1)$ \\
\hline \multirow[t]{3}{*}{ Time of day } & Day & 7896 & 1.6 & $4.4(1)$ \\
\hline & EET & 5634 & 2.1 & $2.9(2)$ \\
\hline & Night & 2702 & 2.9 & $2.9(2)$ \\
\hline \multirow[t]{4}{*}{ Season } & Spring & 7358 & 2.6 & $4.3(2)$ \\
\hline & Summer & 4962 & 0.6 & $1.7(1)$ \\
\hline & Fall & 2359 & 1.4 & $2.4(1)$ \\
\hline & Winter & 1553 & 4.1 & $2.8(2)$ \\
\hline \multirow[t]{2}{*}{ Warning status } & Hit & 10599 & 2.6 & $3.8(2)$ \\
\hline & Miss & 5633 & 0.7 & $1.5(1)$ \\
\hline
\end{tabular}

comprise over half of tornado fatalities, nearly twothirds of deadly tornadoes are rated (E)F2-3.

\section{b. Storm mode}

Isolated tornadic right-moving supercells (RMS) are the "textbook" recipe for deadly tornadoes, although tornadoes spawned by quasi-linear convective systems (QLCS) have also attracted interest, especially in the context of tornadoes occurring in high-shear, low-CAPE environments in the southeastern United States (Thompson et al. 2012; Sherburn et al. 2016). Between 1998 and 2007, Schoen and Ashley (2011) found that more than $90 \%$ of tornado deaths were associated with supercells, and also that supercells resulted in a mean of three fatalities per fatal storm, while other storm modes resulted in values closer to one fatality per fatal storm. Anderson-Frey et al. (2019) also found, for 2003-17, a higher mean percentage of deadly tornadoes with an RMS storm mode versus a QLCS storm mode.

The majority of tornadoes have an RMS storm mode (65.6\%), while only $12.7 \%$ have a QLCS storm mode, and nearly a quarter $(21.7 \%)$ fall into neither category (Fig. 2b). Deadly tornadoes and tornado deaths, however, are even more lopsided: RMS tornadoes make up $89.1 \%$ of deadly tornadoes (the QLCS storm mode is only responsible for $5.0 \%$ ), and $95.6 \%$ of all tornado deaths are from RMS storms (versus only $2.0 \%$ from QLCS storms).

Even among RMS tornadoes, however, deadly tornadoes are a comparative rarity, with only $2.7 \%$ of all RMS tornadoes resulting in at least one death (Table 1). This percentage is still higher than the percentage of deaths among QLCS tornadoes; only $0.8 \%$ of QLCS tornadoes resulted in at least one death. The mean (median) number of deaths for deadly RMS tornadoes is 3.8 (2), versus 1.4 (1) for deadly QLCS tornadoes, which is approximately in line with the results of Schoen and Ashley (2011).

\section{c. Time of day}

Apart from the influence of time of day on the meteorological ingredients for tornadic potential [e.g., Anderson-Frey et al. (2016) found STP to be maximized for tornado events occurring shortly after local sunset], nonmeteorological factors likely also play a role. Overnight, warnings may not be received in a timely manner [Liu et al. (2019) emphasized that the first communication mobile home residents receive about a tornado at night may be a warning], and employees who work in fixed-frame structures may have returned to a less secure mobile home for the evening (Linehan 1957; Schmidlin et al. 2009). Linehan (1957) found, in their early work, that the highest percentage of tornado deaths occurred between 1431 and 1631 LST, with a secondary maximum at 2031 LST, and a minimum at 0531 LST. Expanding the discussion of nocturnal tornadoes, Ashley et al. (2008) found that, between 1950 and $2005,27.3 \%$ of tornadoes occurred overnight but accounted for $39.3 \%$ of tornado deaths and $42.1 \%$ of deadly tornadoes; in a more recent dataset, Schoen and Ashley (2011) determined that 53\% of all fatal tornadoes occurred between 0000 and 0600 UTC, corresponding roughly to the early evening through late-night hours. 
The discrepancies between the three bar plots in Fig. 2c are less dramatic than for some of the other categories depicted in Fig. 2. Daytime tornadoes comprise $48.6 \%$ of all tornadoes and also $49.2 \%$ of all tornado deaths, but a slightly less-than-proportional percentage of deadly tornadoes (39.1\%; Fig. 2c). Over onethird $(34.7 \%)$ of all tornadoes occur in the early evening transition (EET), and similarly, $36.3 \%$ of deadly tornadoes and $30.4 \%$ of tornado deaths occur during this 4 -h nearsunset time period. Only $16.6 \%$ of tornado events occur overnight, but those events are responsible for $24.7 \%$ of deadly tornadoes and $20.4 \%$ of tornado deaths.

Deadly tornadoes are rare across all three time periods (Table 1): they make up $1.6 \%$ of daytime tornadoes, $2.1 \%$ of EET tornadoes, and $2.9 \%$ of nighttime tornadoes. Deadly tornadoes that occur overnight or during the EET are responsible for a lower mean number of deaths (both at 2.9), compared to the mean number of deaths for daytime deadly tornadoes (4.4). In contrast, median numbers of deaths per deadly tornado are highest for the EET and nighttime (2), with a median value of just 1 for daytime.

\section{d. Season}

The seasonality of tornado events, apart from the aforementioned geographical distributions, generally peaks in the spring and is minimized in the cool season (fall and winter). Similarly, both Ashley (2007) and Linehan (1957) found that the mean number of tornado deaths reaches its peak between March and June [Linehan (1957) noted that $83 \%$ of tornadoes between 1916 and 1953 occurred during these months]; Schoen and Ashley (2011) found a peak between February and May, with a secondary peak in November. Tornado deaths are generally lowest in July (Linehan 1957; Schoen and Ashley 2011).

Springtime tornadoes comprise $45.3 \%$ of all tornadoes, but $60.3 \%$ of deadly tornadoes and a whopping $72.9 \%$ of tornado deaths (Fig. 2d). In stark contrast, nearly one-third of all tornadoes occur during summertime months $(30.6 \%)$, but only $9.4 \%$ of deadly tornadoes and $4.5 \%$ of tornado deaths happen during these summer months. Fall tornadoes make up $14.5 \%$ of the dataset, but a slightly less proportionate $10.6 \%$ of deadly tornadoes and only $7.1 \%$ of tornado deaths. Winter tornadoes follow the opposite pattern, making up 9.6\% of all tornadoes but $19.7 \%$ of deadly tornadoes and $15.5 \%$ of tornado deaths. Thus, winter and (especially) spring make up a disproportionately high percentage of deadly tornadoes and tornado deaths, whereas fall and (especially) summer comprise a disproportionately low percentage of deadly tornadoes and tornado deaths.

Deadly tornadoes are a rarity in all seasons, but especially the summer, where they make up only $0.6 \%$ of tornadoes, and the fall, where only $1.4 \%$ of tornadoes are deadly (Table 1$)$. Spring $(2.6 \%)$ and especially winter $(4.1 \%)$ have somewhat higher percentages of tornadoes that result in at least one death. For deadly tornadoes, the mean (median) number of tornado deaths is 4.3 (2) in the spring, 1.7 (1) in the summer, 2.4 (1) in the fall, and 2.8 (2) in the winter.

\section{e. Warning skill}

The connection between warning skill and tornado deaths is inherently complex: Doswell et al. (1999) noted that "increasingly, tornado fatalities are related to bad luck, where actions that normally would suffice to save lives are not sufficient." The risks of not warning tornadoes are generally more obvious than the risk of overwarning: despite widespread discussion of the "cry wolf" effect of false alarm warnings, Lim et al. (2019) found that concerns related to high false alarms generating a complacent public may be overblown. Tornado warning skill measures such as POD and false-alarm ratio generally improve with increasing (E)F scale and more textbook tornado environments with high values of parameters such as CAPE, shear, and storm-relative helicity (e.g., Anderson-Frey et al. 2016), which also generally tend to be environments with high fatality rates; that is, the scenarios in which tornadoes are most dangerous are also the scenarios in which tornado warnings are most skillful [e.g., Galway (1975) found that $66 \%$ of tornado deaths between March 1952 and 1973 happened inside a watch and that $77 \%$ of the tornado deaths occurring during major outbreaks were within watch areas].

Percentages of hits (i.e., events for which a tornado warning was issued in advance; see Brooks and Correia (2018) for discussion of these and other performance metrics) and misses (i.e., events for which a tornado warning was not issued in advance) are highlighted in Fig. 2e. For these fifteen years, $65.0 \%$ of tornado events are hits, but this percentage rises to $87.2 \%$ for deadly tornado events, and $94.7 \%$ of tornado deaths occurred within a tornado warning area; thus, the vast majority of deadly tornadoes are warned in advance.

Successfully warned tornadoes (hits) result in at least one death $2.6 \%$ of the time, versus only $0.7 \%$ of the time for missed tornado events (Table 1). A deadly tornado with a warning out ahead of time results in a mean (median) of 3.8 (2) deaths, whereas a deadly tornado without a warning results in a mean (median) of $1.5(1)$; again, this likely reflects that the scenarios in which tornado warning skill is highest also tend to be the scenarios conducive to more dangerous, and hence deadlier, tornadoes. The median $(\mathrm{E}) \mathrm{F}$-scale rating of a deadly, successfully warned tornado is (E)F3, whereas the median (E)F-scale rating of a deadly, unwarned tornado is 
(E)F2; $92.8 \%$ of successfully warned deadly tornadoes have an RMS parent storm, versus only $62.5 \%$ of unwarned deadly tornadoes. Further discussion of warning skill in the following sections will incorporate environmental and nonmeteorological factors.

\section{f. Geography}

Geography plays a strong role in the distribution of tornado deaths and deadly tornadoes, both due to the distribution of favorable synoptic environments and mesoscale ingredients, and due to nonmeteorological factors such as the region's concentration of mobile homes (Strader and Ashley 2018) and demographics (Schumann et al. 2018). As far back as the first half of the twentieth century, a seasonal shift in the regions of tornado deaths was observed: Linehan (1957) noted that the centroid of tornado deaths moved from east-central Mississippi in February to central Iowa in July and August, then back to the Southeast in January. Ashley (2007) noted that, despite the frequency of tornadoes in the Great Plains, that region has relatively few tornado deaths, with the majority occurring in the Southeast due to its unique juxtaposition of both physical and social vulnerabilities; Anderson-Frey et al. (2019) found that, between 2003 and 2017, the percentage of deadly tornadoes in the Southeast United States (3.8\%) was nearly double the percentage for the United States as a whole $(2.0 \%)$. Further exploring the potential for a tornado disaster in this region in the coming decades, Strader et al. (2017b) noted that the mid-South has the greatest potential due both to a relatively elevated tornado risk and accelerated growth of the developed land area. Ashley and Strader (2016) also highlighted the midSouth's high frequency of EF1+ tornadoes and rapid urban, suburban, and exurban growth between 1950 and 2010. This focus on the Southeast is borne out by the 2003-17 data in Figs. 1b and 1c.

\section{Proximity sounding environments of deadly tornadoes and tornado deaths}

The environments in which tornadoes occur will be summarized in the work that follows using proximity sounding data (i.e., model sounding data as described in section 2) to construct two parameter spaces. The first is mixed-layer convective available potential energy (MLCAPE) and 0-6-km vector shear magnitude (SHR6), and the second is mixed-layer lifting condensation level (MLLCL) and 0-1-km storm-relative helicity (SRH1). These four parameters are the components of one formulation of the significant tornado parameter (STP; Thompson et al. 2003). The STP has been found to discriminate well between significantly severe but nontornadic and significantly tornadic supercell environments (Thompson et al. 2012; Gensini and de Guenni 2019; Grams et al. 2012), and splitting STP into these two parameter spaces provides additional insight (Anderson-Frey et al. 2016).

Figure 3 further demonstrates the importance of distinguishing between deadly tornadoes and tornado deaths, as the environments in which these are maximized vary. Tornado deaths are strongly skewed toward the relatively high-CAPE but low-SRH1 environment of the particularly deadly 22 May 2011 Joplin, MO tornado (bright spot in shading in Fig. 3), whereas deadly tornadoes show that the more "typical" deadly tornado environment is one with relatively moderate values of MLCAPE and relatively low MLLCL heights, along with high SHR6 and SRH1 values.

In the previous section, we found that tornadoes with higher (E)F-scale ratings resulted in a disproportionately high percentage of deadly tornadoes and tornado deaths. Here, (E)F0-1 tornadoes (Figs. 4a,b) show the greatest difference between the distribution of deadly tornado events (red) and nondeadly tornado events (black): deadly tornado events tend generally to occur in somewhat lower-MLCAPE, higher-SHR6, higher-SRH1 regimes. These rare deaths that occur in relatively weak tornadoes are hence characterized by relatively marginal thermodynamics but favorable kinematics, in agreement with the distribution of deadly tornadoes for the entire dataset (Fig. 3). Given that only $0.3 \%$ of (E)F0-1 tornadoes are deadly, however, and that the mean (median) number of deaths per deadly (E)F0-1 tornado is only 1.2 (1), we hypothesize that any environmental differences of these relatively isolated "one-off" fatalities are likely to be less relevant than demographic factors outside the scope of this dataset. For instance, Schumann et al. (2018) highlighted that tornado fatalities are tied to demographic characteristics such as gender, race and ethnicity, and age, as well as previous experience with risks and hazards. This may also simply be the manifestation of the "bad luck" factor invoked by Doswell et al. (1999): single deaths during relatively weak tornadoes may simply be a case of an individual being in the wrong place at the wrong time.

For the significant but not violent tornadoes rated (E)F2-3 (Figs. 4c,d), the difference in both MLCAPE and SHR6 is no longer present. There remains only an offset in SRH1 between deadly tornadoes (red) and nondeadly tornadoes (black), with the former having somewhat larger values of SRH1, although the overlap between the two categories is substantial. Likewise, violent tornadoes rated (E)F4+ (Figs. 4e,f) show almost no difference between deadly and nondeadly tornadoes in either of the parameter spaces explored. With the dubious exception of (E)F0-1 tornadoes, the environments 
(a) Tornado Fatality Environments

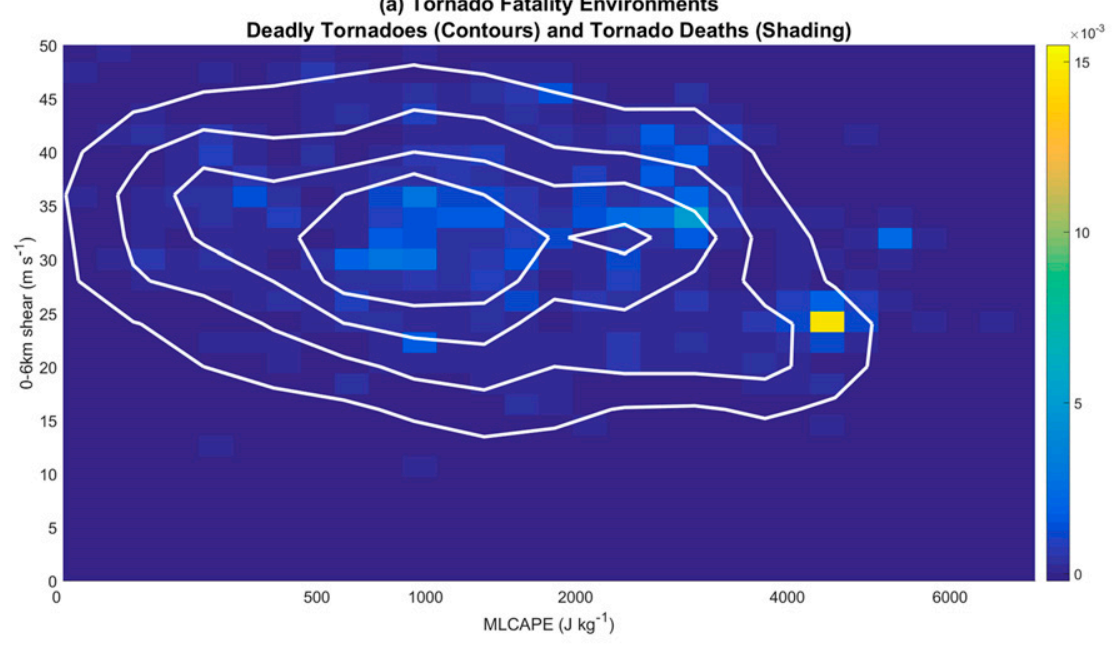

(b) Tornado Fatality Environments

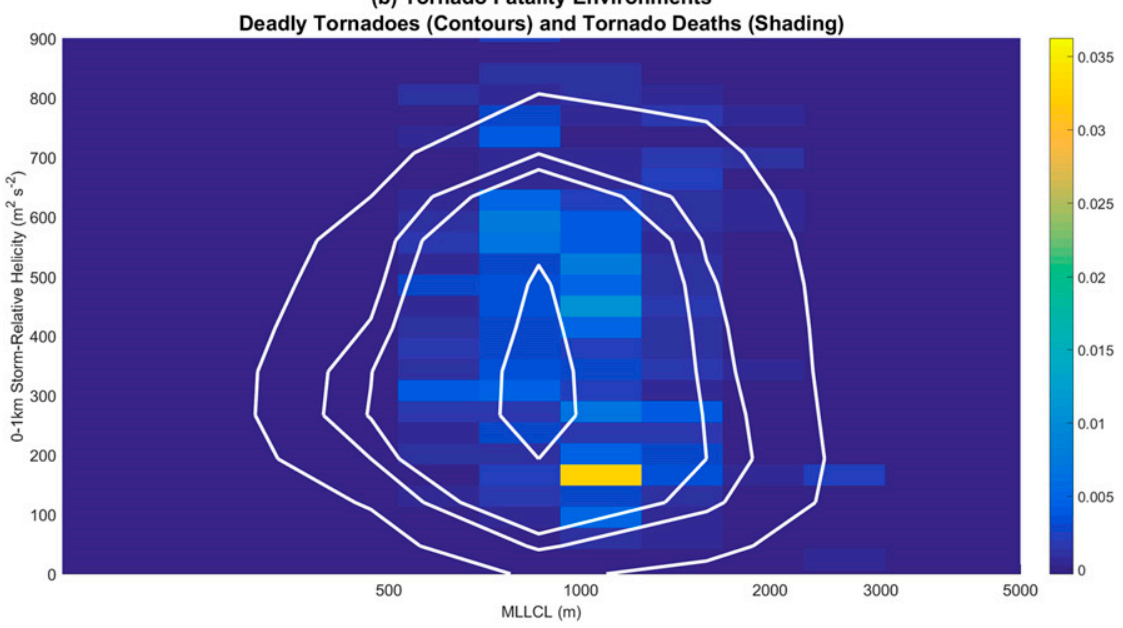

FIG. 3. Tornado fatality environments for the (a) MLCAPE-SHR6 and (b) MLLCL-SRH1 parameter spaces. The environmental distribution of deadly tornadoes is depicted using KDE contours positioned such that each set of contours is centered on the location of highest density of events, with the innermost contour containing $25 \%$ of the data, and, moving outward, subsequent contours containing $50 \%, 75 \%$, and $90 \%$ of the data. The shading is a KDE plot of tornado deaths in the environmental parameter space. Note that MLLCL is plotted on a logarithmic scale and that MLCAPE is plotted on a nonlinear scale [converted to a speed via $w_{\max }=\left(2 \times \mathrm{MLCAPE}^{1 / 2}\right.$ ].

in which tornado fatalities occur are similar across these parameter spaces when separated by (E)F scale.

The next question, then, is whether tornado warning skill across both of these parameter spaces varies for deadly versus nondeadly tornadoes. Unfortunately, as deaths are not recorded for false alarm tornado warnings, false-alarm ratio cannot be computed, but the lead time information in the dataset enables the calculation of POD. Figure 5 plots the POD by environment for deadly and nondeadly tornado events.

Since deadly tornado events are indeed far less common than nondeadly tornado events, they make up a relatively small fraction of the parameter spaces
(Figs. 5a,b), but some weak trends are visible: namely, that POD is generally greater for larger values of SHR6 and especially MLCAPE (Fig. 5a) and is generally greater for larger values of SRH1 and larger values of MLLCL (Fig. 5b), with the caveat that nearly all available MLLCL data are for values less than $1000 \mathrm{~m}$, which doesn't rule out a "sweet spot" value for low-to-moderate MLLCL. These values, however, all line up with the general trends in the nondeadly tornado POD (Figs. 5c,d), though with somewhat higher values, as we might expect given that the POD for deadly tornadoes ( $87.2 \%)$ is higher than that for nondeadly tornadoes $(62.5 \%)$. There are no dramatic reversals apparent in these data: generally 
a. (E)F0-1 Tornado Environments

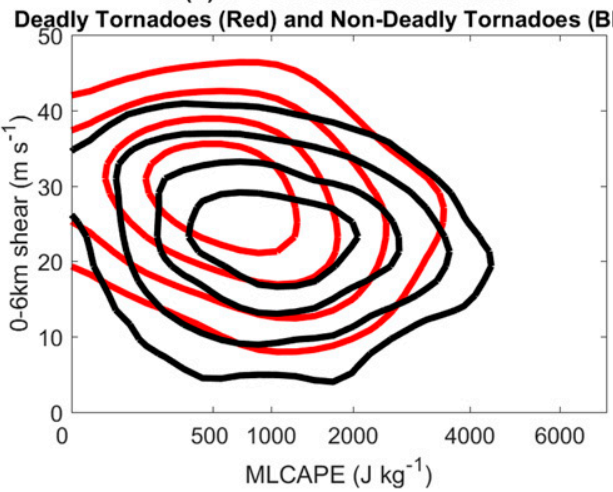

c. (E)F2-3 Tornado Environments

Deadly Tornadoes (Red) and Non-Deadly Tornadoes (Black)

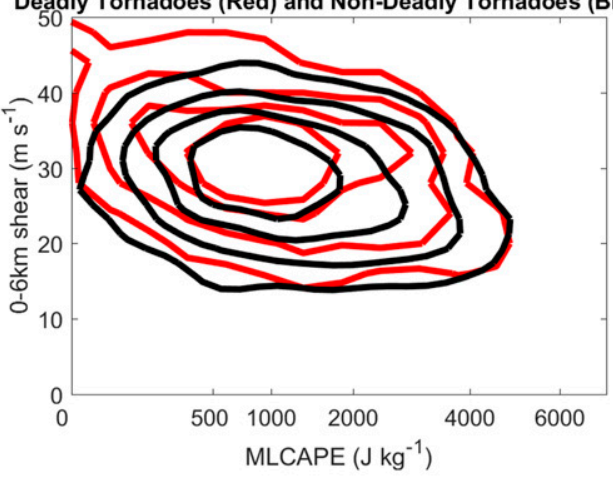

e. (E)F4+ Tornado Environments

Deadly Tornadoes (Red) and Non-Deadly Tornadoes (Black)

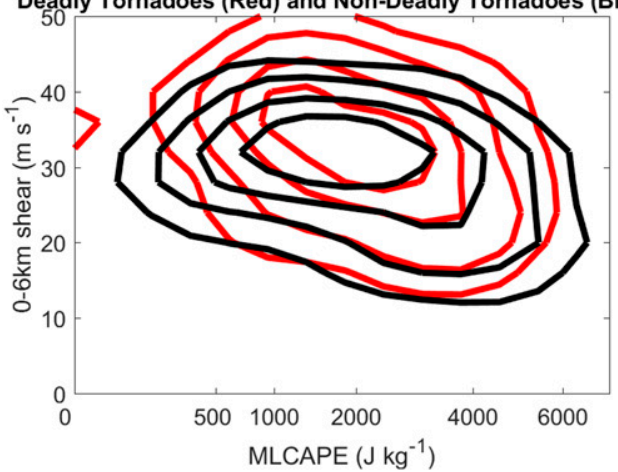

b. (E)F0-1 Tornado Environments

Deadly Tornadoes (Red) and Non-Deadly Tornadoes (Black)

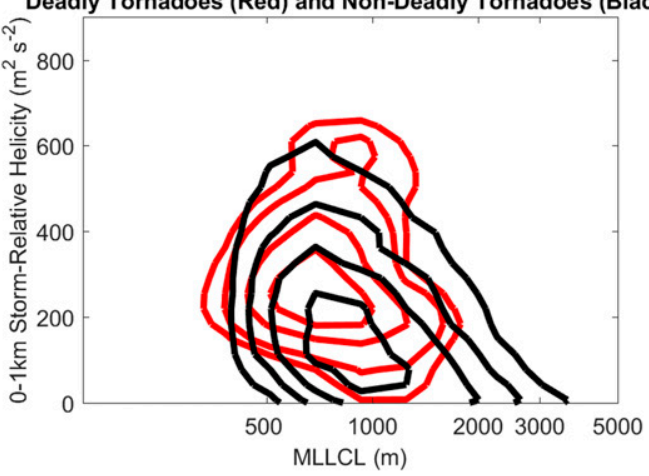

d. (E)F2-3 Tornado Environments

Deadly Tornadoes (Red) and Non-Deadly Tornadoes (Black)

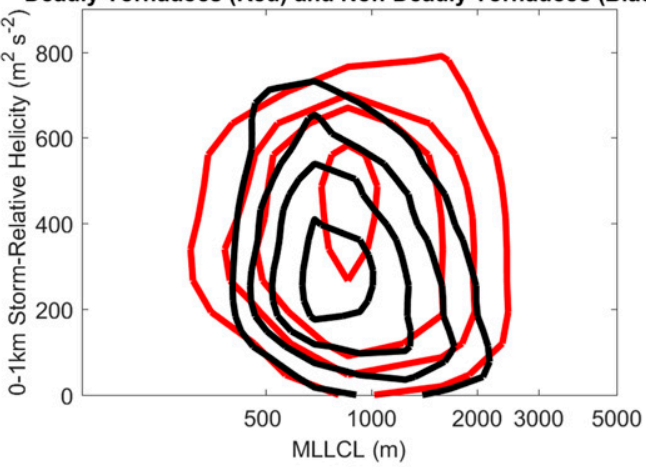

f. (E)F4+ Tornado Environments

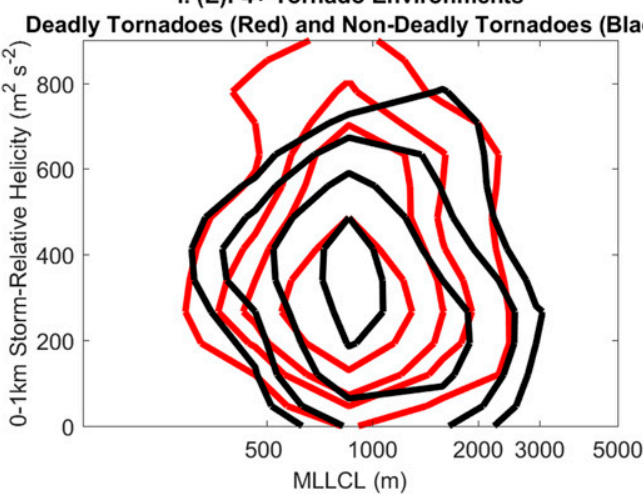

FIG. 4. Gaussian KDE illustrations of (a),(b) (E)F0-1, (c),(d) (E)F2-3, and (e),(f) (E)F4+ tornado events between 2003 and 2017 for the (left) MLCAPE-SHR6 and (right) MLLCL-SRH1 parameter spaces. Red contours are the distributions of tornado events with at least one death, and black contours are the distributions of tornado events with zero deaths, with contours drawn as described in the caption for Fig. 3.

speaking, tornado warning skill does not vary by environment for deadly tornadoes any differently than it does for nondeadly tornadoes, apart from overall higher values.

\section{Self-organizing maps}

\section{a. A two-dimensional perspective}

The proximity-sounding approach of the previous section provides only basic insight into the environments in which deadly tornadoes occur, by assigning a single point value as representative of the environment in which the tornado formed. The SOM approach delineated in section 2 provides a means of discussing the environments of tornado events in terms of the two-dimensional pattern of their environment. Here, we use the fixed-layer STP (Thompson et al. 2003) as a means of summarizing the two parameter spaces in the previous section.

Figure 6 is the SOM that summarizes a subset of mesoanalysis data that includes only deadly tornado events between 2003 and 2015. Each of the four panels is 

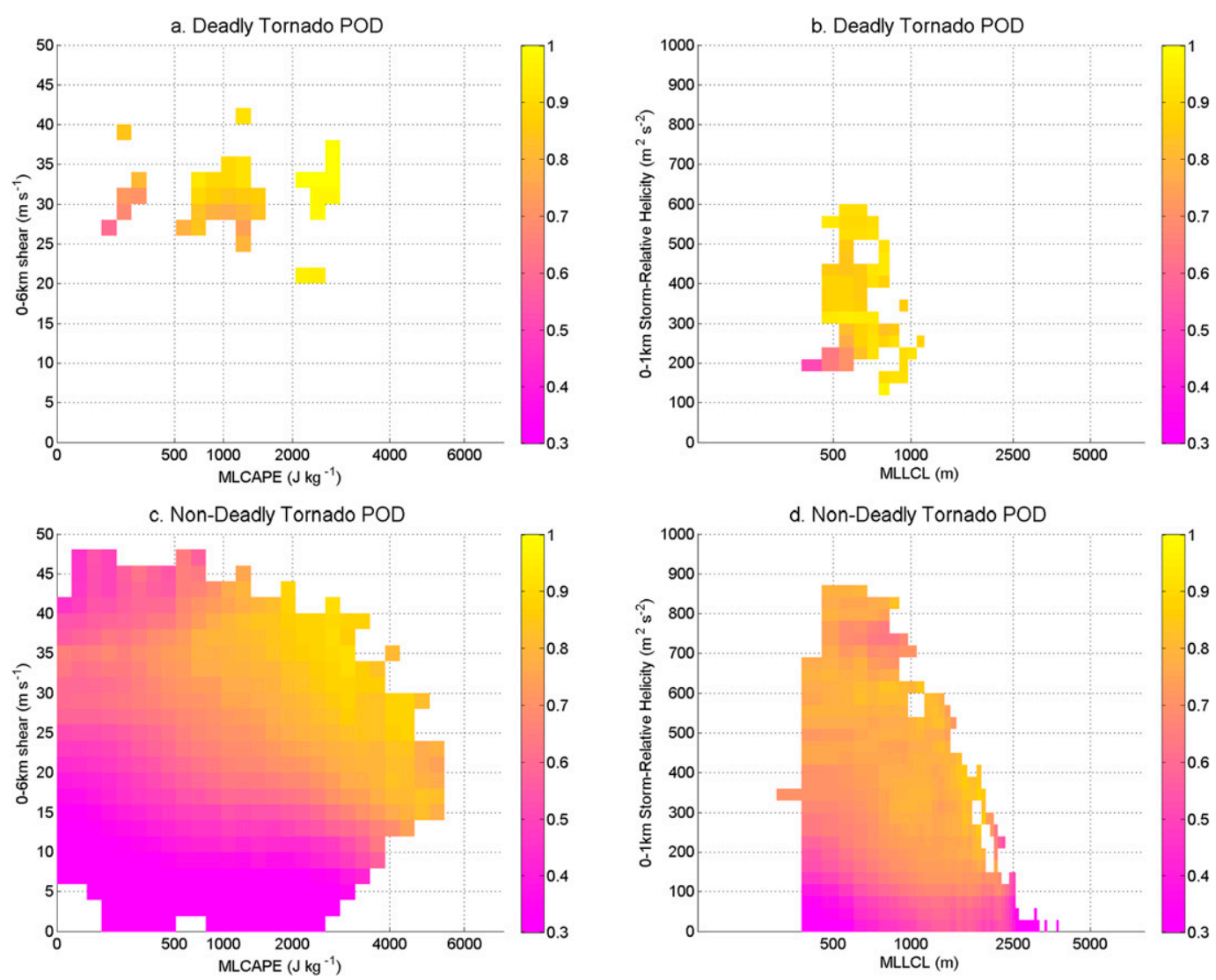

FIG. 5. POD calculated within bins of grid-square dimension (a),(c) $w_{\max }=4 \mathrm{~m} \mathrm{~s}^{-1}$ (where $w_{\max }$ is as defined in the Fig. 3 caption) and SHR6 $=2 \mathrm{~m} \mathrm{~s}^{-1}$ for the MLCAPE-SHR6 parameter space and (b),(d) MLLCL $=75 \mathrm{~m}$ and SRH1 $=30 \mathrm{~m}^{2} \mathrm{~s}^{-2}$ for the MLLCL-SRH1 parameter space for (top) tornado events resulting in at least one death, and (bottom) tornado events resulting in zero deaths. All bins are smoothed using the mean of a $5 \times 5$ bin box surrounding each value.

representative of a typical deadly tornado environment, with the deadly tornado events clustered into each of these mean nodes. The shading is STP values, where values greater than one are generally considered to be more likely to result in significant tornadoes, and the white dot shows the location of the tornado at the center of each of these environments.

Thus, Node 1 in Fig. 6 can be considered to be a truly marginal environment, with STP values less than one but increasing slightly to the south of the tornado. Node 2 is an environment with somewhat higher values of STP, where the tornado is occurring along a tight STP gradient with more favorable environments to the southeast and less favorable environments to the northwest. Node 3 depicts a scenario in which a tornado occurs along the northeastern edge of a broader and more intense region of favorable STP values. Finally, Node 4 has the tornado occurring on the western edge of a tight gradient from near-zero STP values to extreme STP values from west to east.
The mean (median) number of deaths per deadly tornado in Node 1's marginal environment is 2.7 (1); in comparison, Node 2's higher values of STP are associated with a higher mean of 4.3 (median of 2) number of deaths. The danger rises with Node 4's extreme STP environments, with a mean of 3.3 and a median of 3 deaths, but it is Node 3, despite its somewhat lower (but still substantial) STP values, that results in the highest number of deaths, with a mean (median) of 7.0 (4) deaths per deadly tornado.

In contrast, Fig. 7 summarizes the tornado events between 2003 and 2015 that did not result in any reported deaths. Comparing Figs. 6 and 7 shows some similarities: in both SOMs, a node is identified that represents marginal STP values (Node 1), another node has very high STP values (Node 4), and two nodes are intermediate in magnitude between these extremes (Nodes 2 and 3). Note that the extreme-STP node for the nondeadly SOM (Node 4 of Fig. 7) features generally lower values of STP than for the deadly SOM, and also 


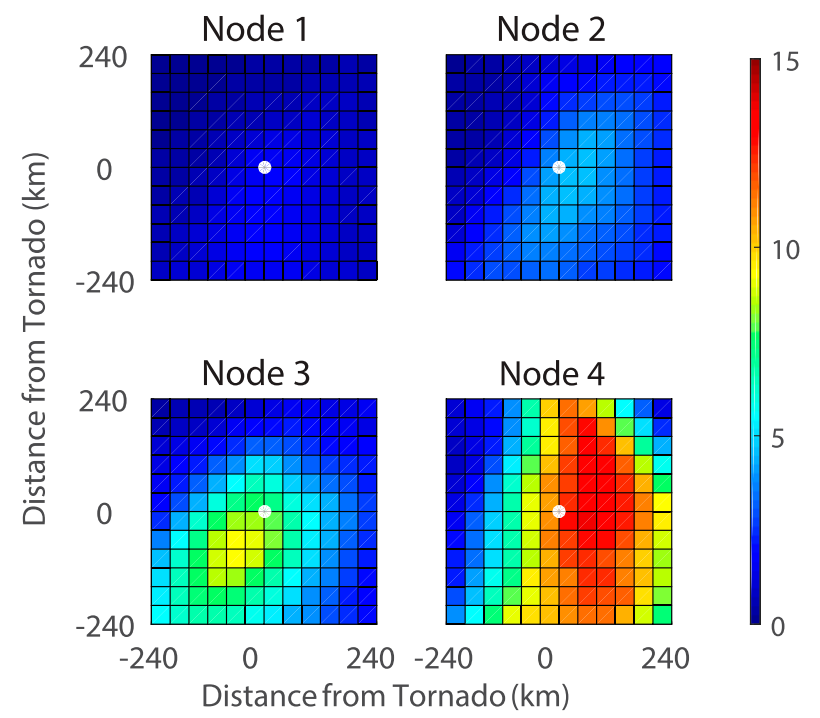

FIG. 6. Results of a SOM carried out for the STP environment of deadly tornado events for $2003-15$, inclusive. Here, $2 \times 2$ nodes have been generated, and this depiction shows the mean STP values for each of the four resulting clusters. The white dot at the center of each node shows the location of the tornado, and the maps extend $240 \mathrm{~km}$ to the north, west, east, and south of each tornado. The numbers of events in clusters 1-4 are, respectively, $161,91,32$, and 12 .

that these high-STP environments of nondeadly tornadoes are centered on the location of the tornado rather than being offset to the east. When tornadoes with extreme STP values result in deaths, the scenario is more often one of a strong east-west gradient in STP than of a uniformly favorable STP environment centered on the tornado.

\section{b. Statistics and findings}

Summary statistics for the SOM introduced in Fig. 6 are depicted in Fig. 8, where summaries have been constructed that correspond to each of the four nodes in order to discuss the characteristics of these STP environments. In terms of (E)F-scale rating (Fig. 8a), Node 1 is an environment with a relatively high share of (E)F0-1 tornadoes: nearly $20 \%$ of all deadly tornado events sorted into that node are rated $(\mathrm{E}) \mathrm{F} 0-1$, whereas for the deadly tornado dataset as a whole, only $11.9 \%$ are (E)F0-1 (Fig. 2a). In fact, Node 1 is the only node in which (E)F0 tornadoes appear; Node 2 (an environment with moderate STP values northeast of the tornado) has a small percentage of $(\mathrm{E}) \mathrm{F} 1$ tornadoes but is made up almost exclusively of (E)F2 + tornadoes. Interestingly, Node 3 contains a much higher percentage of (E)F4+ tornadoes $(>60 \%)$ than Node 4 (closer to $20 \%$ ), despite Node 4's much more extreme STP environment; the vast majority of Node 4's extreme-STP

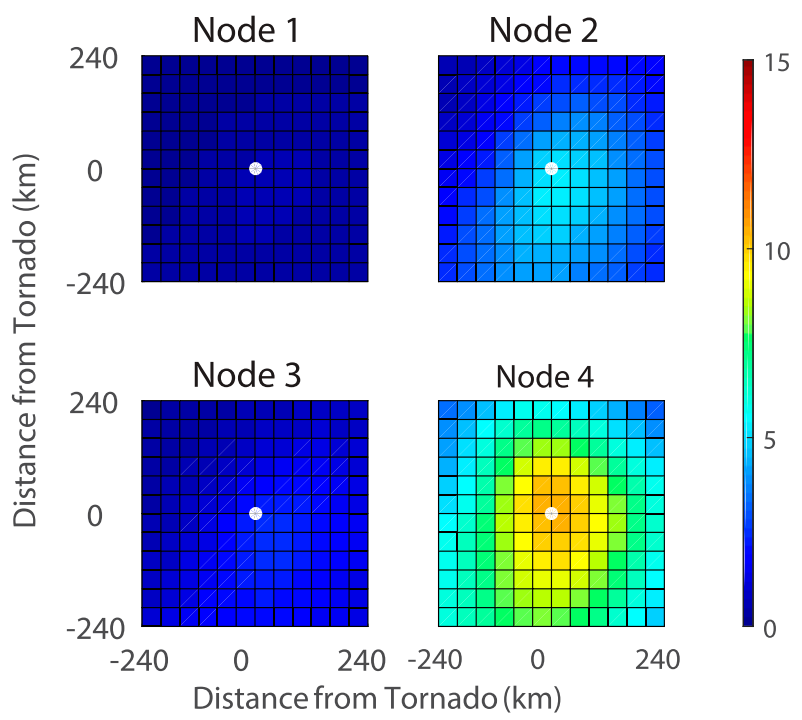

FIG. 7. As in Fig. 6, but for tornadoes resulting in zero deaths. The numbers of events in clusters $1-4$ are, respectively, 8527, 1115, 3800 , and 168 .

cases are rated $(\mathrm{E}) \mathrm{F} 3$, and its mean and median number of deaths per deadly tornado is somewhat lower as a result. In fact, Node 4 has fewer (E)F5 tornadoes than any of the other three. Looking at the (E)F-scale distribution for each of these nodes, the storm mode results in Fig. 8b should be unsurprising: only the marginal Node 1 contains any QLCS or Other (i.e., non-RMS and non-QLCS) storm modes, with Nodes 2, 3, and 4 all containing $100 \%$ right-moving supercells.

We know from Fig. 2c that deadly tornadoes are somewhat disproportionately more likely at night, but we can now see (Fig. 8c) that these deadly nighttime tornadoes happen much more often in the more marginal Node 1 and Node 2 scenarios, rather than the more dangerous [i.e., higher fatality and higher (E)F scale] Nodes 3 and 4. Thus, while nocturnal tornadoes make up a disproportionately high percentage of all deadly tornadoes (Fig. 2c), those nocturnal deaths tend to occur in more marginal tornadic environments.

From Fig. 2d, deadly tornadoes are disproportionately likely to occur during the spring and winter months. Figure 8d shows that the more marginal Nodes 1 and 2 are characterized by relatively few springtime events, but disproportionately more winter events, especially in Node 1 . The vast majority of the events sorted into Nodes 3 and 4 occur during the springtime, and neither of these nodes contain any wintertime tornado events. Thus, similar to the results for nocturnal tornadoes, while winter tornadoes are a disproportionately high fraction of all deadly tornadoes, deadly winter tornadoes occur in more marginal tornadic environments. 
(a) (E)F-Scale Rating

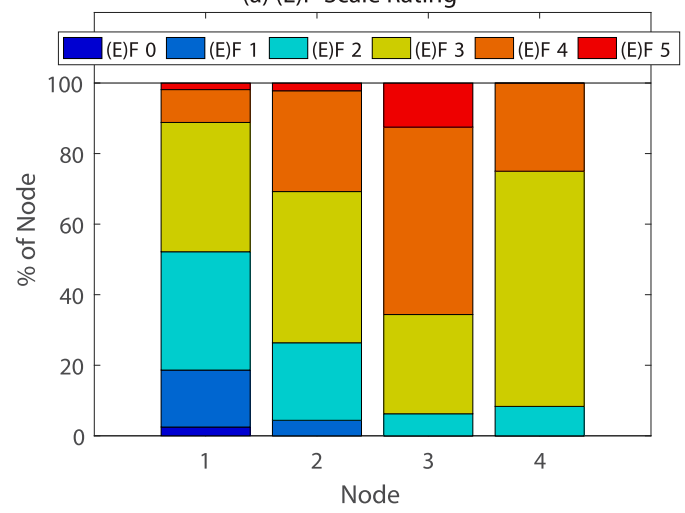

(c) Time of Day

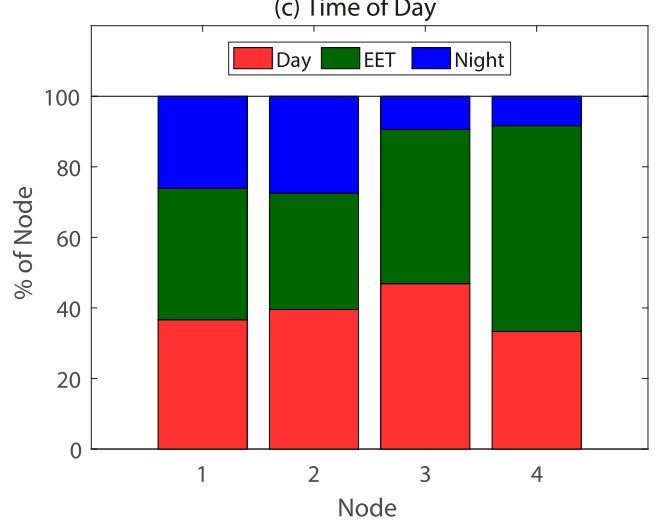

(b) Storm Mode
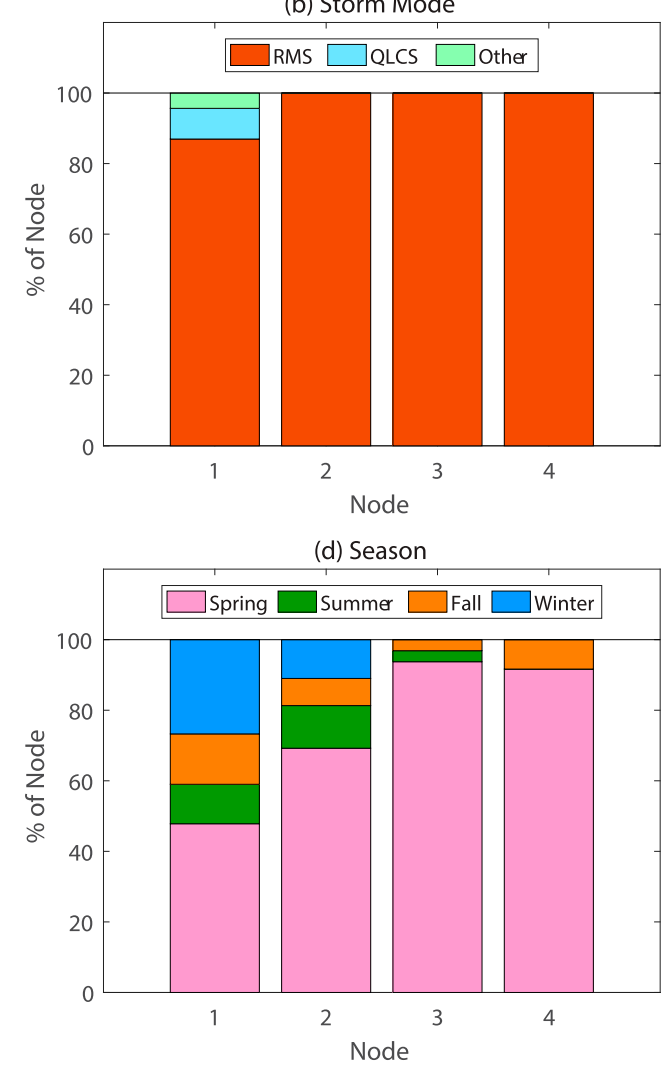

(e) Warning Skill

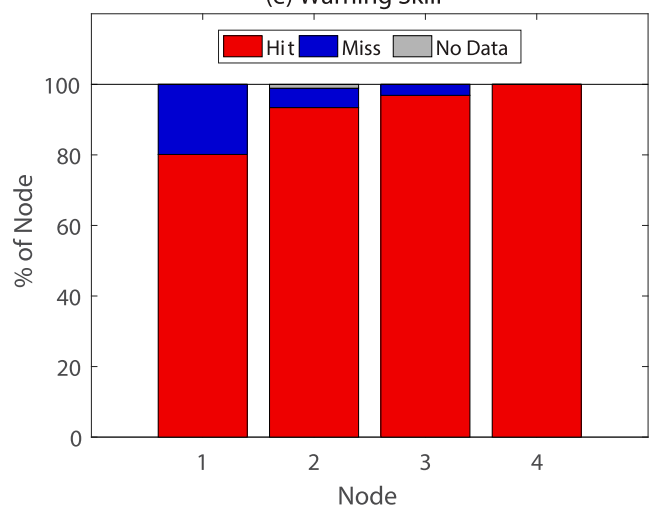

FIG. 8. Statistics pertaining to the four SOM nodes depicted in Fig. 6: (a) (E)F scale, (b) storm mode, (c) time of day,

(d) season, and (e) warning skill composition for each node. Categories are as defined in the caption for Fig. 2.

Finally, tornado warning skill (i.e., POD) increases with increasing mean values of STP in each node's environment, as suggested by Fig. 5 and found in previous work (e.g., Anderson-Frey et al. 2017). Despite including more (E)F5 tornadoes and fewer (E)F2-3 tornadoes, the POD for Node 3 is slightly lower than Node 4's perfect $100 \%$.

Figure 9a shows an immediate contrast to Fig. 8a that highlights a previous finding: the vast majority of nondeadly environments are rated $(\mathrm{E}) \mathrm{F} 0$ or $(\mathrm{E}) \mathrm{F} 1$, regardless of node. In fact, even the relatively extreme node (Node 4 in Fig. 7) has an only slightly higher percentage of (E)F2 + tornadoes $(29.2 \%)$ when compared with the lower-STP Nodes $2(27.5 \%)$ or $3(18.8 \%)$. In terms of storm mode (Fig. 9b), Nodes 2 and 4 have the highest percentage of RMS tornadoes $(90.0 \%$ and $91.1 \%$, respectively), which is comparable to the percentage of RMS tornadoes in the most marginal node of the deadly tornado SOM (Node 1 in Fig. 8b): 87.0\%. More than a third of all tornadoes in the nondeadly tornado 
SOM's Node 1 do not originate from right-moving supercells.

Time of day (Fig. 9c) and season (Fig. 9d) for nondeadly tornadoes both show an overall shift when compared to deadly tornadoes: nondeadly tornadoes generally have a slightly lower percentage of EET tornadoes and a substantially lower percentage of springtime tornadoes across all nodes. A noteworthy exception is the extreme-STP node (Node 4 in Fig. 7), which has a seasonal composition that is nearly identical to its analogous node in the deadly tornado dataset (Node 4 in Fig. 6); extreme-STP values occur preferentially in the spring (and very seldom in the fall) for both deadly and nondeadly tornadoes. This outcomeagnostic result suggests that, in the case of extremely high-STP environments, neither season nor spatial distribution of STP (e.g., centered on tornado versus tight east-west gradient) can distinguish between deadly and nondeadly tornadoes. However, these extreme-STP values (Node 4 in both SOMs) occur preferentially in the EET for deadly tornadoes, and at night for nondeadly tornadoes. Finally, POD (Fig. 9e) again shows a tendency to increase with increasing mean values of STP.

Based on the information in Fig. 8, we can characterize these four prototypical deadly tornado environments as follows:

- Node 1 is a somewhat more commonly occurring deadly tornado environment than the other three, featuring marginal values of STP focused just to the south of the tornado. These tornado events include a relatively high share of (E)F0-1 tornadoes and are the environment in which all deadly nonsupercellular tornadoes occurred, but Node 1 is still composed of a majority of significant tornadoes $[(\mathrm{E}) \mathrm{F} 2+]$ and RMS tornadoes. This node includes a disproportionate percentage of nighttime and winter tornadoes, and, given its marginal environmental appearance, has a slightly lower POD than the other nodes (although still higher than nondeadly tornadoes as a whole).

- Node 2 also occurs fairly frequently and is characterized by a deadly tornado occurring on the northwestern edge of a SW-NE oriented band of more favorable tornado environments. Nearly all of these tornadoes are significant $[(\mathrm{E}) \mathrm{F} 2+]$, and all have an RMS storm mode. Nighttime tornadoes are somewhat disproportionately likely in this environment, and while deadly tornadoes from all seasons are sorted into this node, only springtime tornadoes are notably disproportionately likely. POD is very high for these events.

- Node 3 is a less common scenario that can be described as a deadly tornado located on the northeastern corner of a region of high STP, analogous to a "triple-point"
(Wakimoto et al. 2006) from a forecasting perspective. This node encompasses an extremely disproportionately high percentage of violent $[(\mathrm{E}) \mathrm{F} 4+]$ tornadoes, all of which are RMS. Fewer of this node's tornadoes occur at night than we would expect given the distribution for the dataset as a whole, and these tornadoes almost all occur during the springtime. POD is very high for these events.

- Node 4 is a rare deadly tornado environment featuring an extreme east-west gradient of STP, with the tornado located on the western edge of the extremely favorable STP values. While there are no (E)F5 tornadoes sorted into this node, the majority are (E)F3-4, all are RMS tornadoes, and a disproportionate fraction occur in the four hours around local sunset and during the springtime. All of these tornadoes were warned in advance, with a POD of $100 \%$. In contrast, for nondeadly tornadoes, extreme-STP events tended to have their most favorable values centered on the location of the tornado (Node 4 of Fig. 7), rather than on the eastern side of a tight gradient centered on the location of the tornado.

\section{c. Cautionary notes regarding the SOM approach}

We note that the sample sizes for the nondeadly tornado events are considerably larger than those for the deadly tornado events (cf. captions of Figs. 6 and 7). Thus, the more tornado-centered extreme values of STP in Node 4 for nondeadly tornadoes (Fig. 7), when compared to the gradient in STP in Node 4 for deadly tornadoes (Fig. 6), could conceivably have been the result of the smoothing of a larger variety of patterns of STP. In this case, however, plotting each of these 168 nondeadly Node 4 environments separately (not shown) does indeed yield a majority of environments featuring a more central location of extreme STP values.

We further note that the most common nodes with the highest number of events and the most marginal environments (Node 1 in Figs. 6 and 7) could also simply be the result of oversmoothing when calculating the mean STP of the larger number of events, rather than a commonly occurring marginal-STP environment. In this case, for the nondeadly SOM's decidedly marginal Node 1 (Fig. 7), only $1 \%$ of events contained a value of STP greater than 3.0 (only 9\% contained a value of STP greater than 1.0), in comparison with the more extreme Node 4's 70\% of events with STP greater than 3.0 (and $77 \%$ with STP greater than 1.0).

Readers should always exercise caution when interpreting the results of SOMs, especially when only the mean value of the node is plotted; there is a necessary trade-off between the simplicity of the final output and 
(a) (E)F-Scale Rating
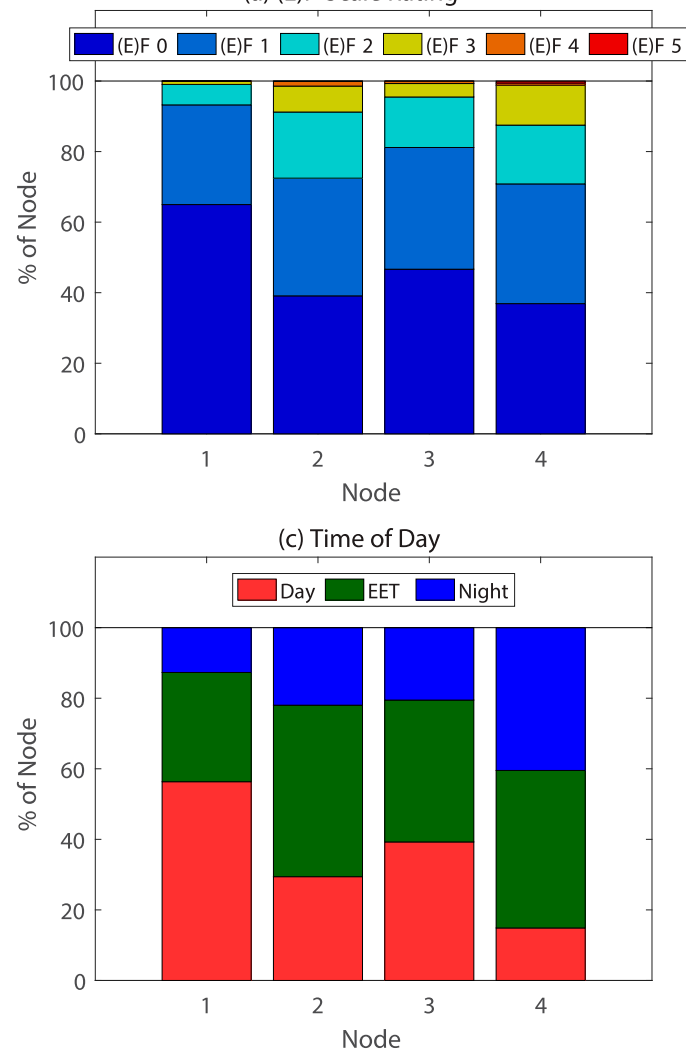

(b) Storm Mode

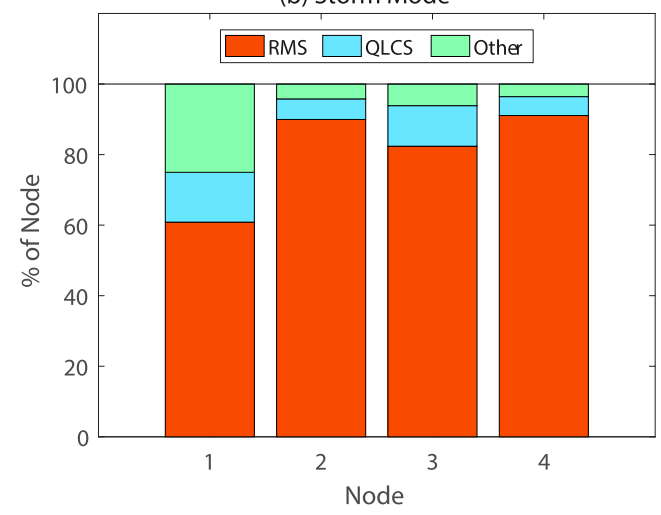

(d) Season

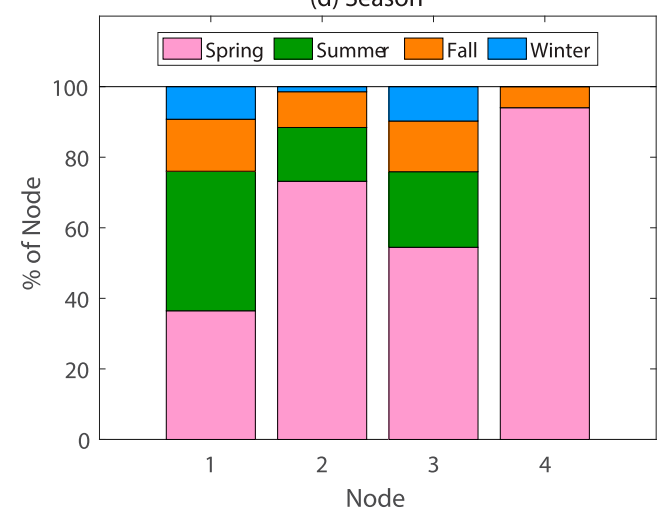

(e) Warning Skill

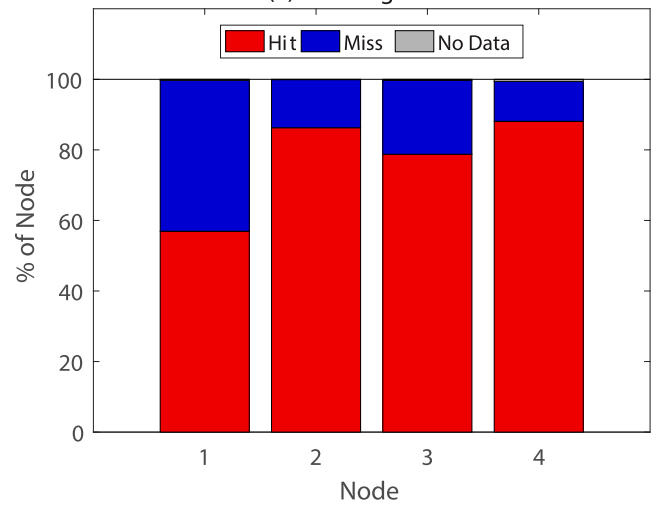

FIG. 9. As in Fig. 8, but for tornadoes resulting in zero deaths.

the complexity of the underlying results. Future work will evaluate more sophisticated visualization methods in order to reflect the full range of events sorted into each node.

\section{Conclusions and recommendations}

Tornadoes are a rare event, and deadly tornadoes are even rarer. The comparative rarity of deaths in tornadoes, however, is not a constant for all situations: much of the study of tornado fatalities is based on identifying, targeting, and developing strategies for the scenarios in which tornado deaths are disproportionately likely. In this work, we both summarize and update some earlier research on the topic of tornado fatality statistics and develop a means by which environmental data can add to the conversation about tornado fatalities.

Our conclusions and recommendations for researchers and forecasters are as follows:

- When discussing fatalities in tornadoes, it is important to report statistics related to both deadly tornadoes and tornado deaths to get a more nuanced summary of the data (e.g., Fig. 3). 
- Given the outlier influence of a very small number of particularly disastrous tornado fatality events, any discussion of the number of deaths per deadly tornado should report both the median and the mean; percentiles would also add to the discussion in a substantive way.

- While QLCS storm modes do periodically result in deadly tornadoes (Fig. 2b), they are disporportionately unlikely to be deadly, and almost vanishingly unlikely to result in multiple deaths. A disproportionate majority of deadly tornadoes, even in decidedly marginal near-storm environments (e.g., Fig. 8b), still have an RMS storm mode.

- Deadly tornadoes have a much higher POD than nondeadly tornadoes. The results in Fig. 4 confirm that, for a given $(\mathrm{E}) \mathrm{F}$ scale, the environments in which deadly and nondeadly tornadoes form are generally similar. Thus, while it is not readily apparent how to discriminate environmentally between a deadly (E)F3 tornado and a nondeadly (E)F3 tornado, discriminating environmentally between a likely deadly (E)F5 tornado and a rarely deadly (E)F0 tornado is considerably more straightforward. Put another way, the environments in which deadly tornadoes are well-warned are also the environments in which nondeadly tornadoes are well-warned (Fig. 5), but those environments happen to be more conducive to high-(E)F-scale, more-likely-to-be-deadly tornadoes.

- Based on this dataset, point environmental data (e.g., proximity sounding information) provide limited information about the environments in which deadly tornadoes occur. A more promising approach is to consider the broader, (at least) two-dimensional picture of the environments of deadly tornadoes. Following this approach, we have built a SOM (Figs. 6 and 8) and have found that nighttime and winter tornadoes, both of which are responsible for a disproportionately high fraction of deadly tornadoes, also tend to occur in marginal environments that have historically been associated with lower warning skill. Larger datasets would enable larger SOMs; $2 \times 3$ or even $3 \times$ 3 nodes could help highlight differences related to deadly tornado environments in which STP magnitudes are similar but two-dimensional patterns are different.

- As an example of the significance of two-dimensional patterns in STP, the highest-STP environments for deadly (Node 4 in Fig. 6) and nondeadly (Node 4 in Fig. 7) tornadoes show different distributions of those high-STP values. For deadly tornadoes with high STP, these high STP values are generally located to the east of the tornado, with the tornado centered on a tight east-west gradient reminiscent of a linear feature such as a dryline. For nondeadly tornadoes with high STP, these high STP values are generally centered on the location of the tornado, suggesting a less linear parent environment.

- Despite the disproportionately high percentage of tornado deaths in violent tornadoes, half of tornado deaths occur in tornadoes rated (E)F3 or lower (Fig. 2a); Sutter and Simmons (2010) found that $82 \%$ of fatalities in mobile homes occurred in tornadoes rated F3 or lower, and Brooks and Doswell (2002) found that mobile home residents made up about half of all fatalities from 1996 to 2000. This number has since been updated by Strader and Ashley (2018): 54\% of all housing-related fatalities from 1985 to 2019 occurred in mobile or manufactured housing, and in Alabama, Georgia, Mississippi, and Tennessee, $41 \%$ of all tornado fatalities occurred in mobile or manufactured homes, with this percentage rising to $52 \%$ with the omission of the 27 April 2011 outbreak (which contained many deaths in permanent homes). Reducing fatality rates for mobile home residents through retrofitting or new construction [e.g., concrete foundations, anchor bolts, hurricane ties; Strader et al. (2019) noted that complete destruction of a mobile or manufactured home requires wind loads only $45 \%$ as strong as those expected to destroy permanent homes] as well as providing tornado shelters and safe rooms (Strader and Ashley 2018; Strader et al. 2017b) would in turn help to reduce fatality rates for these lower(E)F-scale tornado events. It is also worth noting that these tornado events often occur in more marginal, difficult-to-forecast environments.

- In an early survey of tornado deaths in the United States, Linehan (1957) claimed that the social-science aspects of the tornado fatality problem would not be feasible to study: "Though it is obviously impossible to prove it, the decline in the number of deaths seems most likely to have resulted from improved storm warnings and better use of these warnings by the public." We now have at our disposal a much more substantial modern bulk of literature on the topic to help direct future research and collaborations. In two separate deadly tornado events, Brooks and Doswell (2002; 3 May 1999) and Chiu et al. (2013; 27 April 2011) found that the lowest-risk age groups were 5-14 and 15-24, highlighting the importance of the education of school children. Schmidlin et al. (2009) found that only $31 \%$ of mobile home residents follow NWS recommendations for sheltering during tornadoes, and Ash (2017) delineated the reasons: confusion over where/when to go, but also prioritizing protective actions for both themselves and their homes in response to more likely threats (most notably flash flooding and 
lightning). Chiu et al. (2013) recommended promoting word-of-mouth warnings ("hear a warning, tell a friend") when it is safe to do so, whereas Schumann et al. (2018) noted that the single greatest factor that predicts warning response during a tornado is visual interpretation of a warning graphic, and Stokoe (2016) highlighted that it is essential to translate alerts into Spanish and strongly recommends the development of an official alert and forecast app. In addition, tornadoresilient building codes have been recommended in the civil engineering literature (e.g., Ramseyer et al. 2016; Prevatt 2013). The depth and breadth of these endeavors will help bridge the gulf of understanding those tornado fatalities for which improved meteorological knowledge would have made little or no difference.

Doswell et al. (1999) provided a rough estimate of "on the order of 10000 lives spared" by steps taken in the wake of the early efforts of Fawbush and Miller when they issued the first tornado forecasts at Tinker Air Force Base in 1948. In the face of likely increases in both risk and exposure in the coming century (Strader et al. 2017b), these tremendous strides in forecasting, alongside the meteorological and social science advances of more recent decades, have provided us with a running start to meet the forecasting and research challenges of preventing deaths in tornadoes.

Acknowledgments. The authors thank Bryan Smith, Rich Thompson, and Andy Dean for assistance obtaining and interpreting the storm mode, warning skill, and mesoanalysis datasets, and Patrick Marsh for providing early comments. This manuscript was greatly improved thanks to the efforts of three anonymous reviewers and Matthew Bunkers. Funding was provided by NOAA/Office of Oceanic and Atmospheric Research under NOAAUniversity of Oklahoma Cooperative Agreement NA16OAR4320115, U.S. Department of Commerce.

\section{REFERENCES}

Anderson-Frey, A., Y. Richardson, A. Dean, R. Thompson, and B. Smith, 2016: Investigation of near-storm environments for tornado events and warnings. Wea. Forecasting, 31, 1771-1790, https://doi.org/10.1175/WAF-D-16-0046.1.

,,,,---- and,- 2017 : Self-organizing maps for the investigation of tornadic near-storm environments. Wea. Forecasting, 32, 1467-1475, https://doi.org/10.1175/WAF-D17-0034.1.

,,,,---- and,- 2018 : Near-storm environments of outbreak and isolated tornadoes. Wea. Forecasting, 33, 13971412, https://doi.org/10.1175/WAF-D-18-0057.1.

$-,-\longrightarrow,-$, and,- 2019 : Characteristics of tornado events and warnings in the southeastern United States. Wea. Forecasting, 34, 1017-1034, https://doi.org/10.1175/WAF-D18-0211.1.
Ash, K., 2017: A qualitative study of mobile home resident perspectives on tornadoes and tornado protective actions in South Carolina, USA. GeoJournal, 82, 533-552, https:// doi.org/10.1007/s10708-016-9700-8.

Ashley, W., 2007: Spatial and temporal analysis of tornado fatalities in the United States: 1880-2005. Wea. Forecasting, 22, 1214-1228, https://doi.org/10.1175/2007WAF2007004.1.

_ ingredients of risk and exposure are changing the tornado disaster landscape. Bull. Amer. Meteor. Soc., 97, 767-786, https://doi.org/10.1175/BAMS-D-15-00150.1.

_ A. Krmenec, and R. Schwantes, 2008: Vulnerability due to nocturnal tornadoes. Wea. Forecasting, 23, 795-807, https:// doi.org/10.1175/2008WAF2222132.1.

Benjamin, S., and Coauthors, 2004: An hourly assimilation-forecast cycle: The RUC. Mon. Wea. Rev., 132, 495-518, https://doi.org/ 10.1175/1520-0493(2004)132<0495:AHACTR>2.0.CO;2.

_- and Coauthors, 2016: A North American hourly assimilation and model forecast cycle: The Rapid Refresh. Mon. Wea. Rev., 144, 1669-1694, https://doi.org/10.1175/MWR-D-15-0242.1.

Bothwell, P., J. Hart, and R. Thompson, 2002: An integrated threedimensional objective analysis scheme in use at the Storm Prediction Center. Preprints, 21st Conf. on Severe Local Storms/19th Conf. on Weather Analysis and Forecasting/15th Conf. on Numerical Weather Prediction, San Antonio, TX, Amer. Meteor. Soc., JP3.1, https://ams.confex.com/ams/ SLS_WAF_NWP/techprogram/paper_47482.htm.

Brooks, H., and C. Doswell III, 2001: Normalized damage from major tornadoes in the United States: 1890-1999. Wea. Forecasting, 16, 168-176, https://doi.org/10.1175/1520-0434(2001) $016<0168$ :NDFMTI $>2.0 . \mathrm{CO} ; 2$.

— , and — 2002: Deaths in the 3 May 1999 Oklahoma City tornado from a historical perspective. Wea. Forecasting, 17, 354-361, https://doi.org/10.1175/1520-0434(2002)017<0354: DITMOC $>2.0 . \mathrm{CO} ; 2$.

— National Weather Service tornado warnings. Wea. Forecasting, 33, 1501-1511, https://doi.org/10.1175/WAF-D-18-0120.1.

Brown, S., P. Archer, E. Kruger, and S. Mallonee, 2002: Tornadorelated deaths and injuries in Oklahoma due to the 3 May 1999 tornadoes. Wea. Forecasting, 17, 343-353, https://doi.org/ 10.1175/1520-0434(2002)017<0343:TRDAII >2.0.CO;2.

Chiu, C., A. Schnall, C. Mertzlufft, R. Noe, A. Wolkin, J. Spears, M. Casey-Lockyer, and S. Vagi, 2013: Mortality from a tornado outbreak, Alabama, April 27, 2011. Amer. J. Public Health, 103, e52-e58, https://doi.org/10.2105/AJPH.2013.301291.

Daley, W., S. Brown, P. Archer, E. Kruger, F. Jordan, D. Batts, and S. Mallonee, 2005: Risk of tornado-related death and injury in Oklahoma, May 3, 1999. Amer. J. Epidemiol., 161, 1144-1150, https://doi.org/10.1093/aje/kwi142.

Doswell, C., III, A. Moller, and H. Brooks, 1999: Storm spotting and public awareness since the first tornado forecasts of 1948 . Wea. Forecasting, 14, 544-557, https://doi.org/10.1175/15200434(1999) $014<0544:$ SSAPAS $>2.0$.CO;2.

Galway, J., 1975: Relationship of tornado deaths to severe weather watch areas. Mon. Wea. Rev., 103, 737-741, https://doi.org/ 10.1175/1520-0493(1975)103<0737:ROTDTS > 2.0.CO;2.

Gensini, V., and B. de Guenni, 2019: Environmental covariate representation of seasonal U.S. tornado frequency. J. Appl. Meteor. Climatol., 58, 1353-1367, https://doi.org/10.1175/ JAMC-D-18-0305.1.

Grams, J., R. Thompson, D. Snively, J. Prentice, G. Hodges, and L. Reames, 2012: A climatology and comparison of parameters 
for significant tornado events in the United States. Wea. Forecasting, 27, 106-123, https://doi.org/10.1175/WAF-D-1100008.1.

Kohonen, T., 1982: Self-organized formation of topologically correct feature maps. Biol. Cybern., 43, 59-69, https://oi.org/ 10.1007/BF00337288.

Lim, J., B. Liu, and M. Egnoto, 2019: Cry wolf effect? Evaluating the impact of false alarms on public responses to tornado alerts in the southeastern United States. Wea. Climate Soc., 11, 549563, https://doi.org/10.1175/WCAS-D-18-0080.1.

Linehan, U., 1957: Tornado deaths in the United States. U.S. Department of Commerce, Weather Bureau, $48 \mathrm{pp}$.

Liu, B., M. Egnoto, and J. Lim, 2019: How mobile home residents understand the response to tornado warnings. Wea. Climate Soc., 11, 521-534, https://doi.org/10.1175/WCAS-D-170080.1.

Molina, M., J. Allen, and V. Gensini, 2018: The Gulf of Mexico and ENSO influence on subseasonal and seasonal CONUS winter tornado variability. J. Appl. Meteor. Climatol., 57, 2439-2463, https://doi.org/10.1175/JAMC-D-18-0046.1.

Nowotarski, C., and A. Jensen, 2013: Classifying proximity soundings with self-organizing maps toward improving supercell and tornado forecasting. Wea. Forecasting, 28, 783-801, https://doi.org/10.1175/WAF-D-12-00125.1.

Paul, B., and M. Stimers, 2014: Spatial analyses of the 2011 Joplin tornado mortality: Deaths by interpolated damage zones and location of victims. Wea. Climate Soc., 6, 161-174, https:// doi.org/10.1175/WCAS-D-13-00022.1.

Prevatt, D., 2013: Joplin, Missouri tornado of May 22, 2011: Structural damage survey and case for tornado-resilient building codes. American Society of Civil Engineers, 54 pp.

Ramseyer, C., L. Holliday, and F. Royce, 2016: Enhanced residential building code for tornado safety. J. Perform. Constr. Facil., 30, 832, https://doi.org/10.1061/(ASCE)CF.1943-5509.0000832.

Schmidlin, T., B. Hammer, and J. Knabe, 2009: Tornado shelterseeking behavior and tornado shelter options among mobile home residents in the United States. Nat. Hazards, 48, 191-201, https://doi.org/10.1007/s11069-008-9257-z.

Schoen, J., and W. Ashley, 2011: A climatology of fatal convective wind events by storm type. Wea. Forecasting, 26, 109-121, https://doi.org/10.1175/2010WAF2222428.1.

Schumann, R., III, K. Ash, and G. Bowser, 2018: Tornado warning perception and response: Integrating the roles of visual design, demographics, and hazard experience. Risk Anal., 38, 311-332, https://doi.org/10.1111/risa.12837.

Sherburn, K., M. Parker, J. King, and G. Lackmann, 2016: Composite environments of severe and nonsevere high-shear, low-CAPE convective events. Wea. Forecasting, 31, 18991927, https://doi.org/10.1175/WAF-D-16-0086.1
Simmons, K., and D. Sutter, 2005: Protection from nature's fury: An analysis of fatalities and injuries from F5 tornadoes. Nat. Hazards Rev., 6, 82-87, https://doi.org/10.1061/(ASCE)15276988(2005)6:2(82).

, and - 2011: Economic and Societal Impacts of Tornadoes. Amer. Meteor. Soc., 282 pp.

— , and 2012: Deadly Season: Analysis of the 2011 Tornado Outbreaks. Amer. Meteor. Soc., 120 pp.

Smith, B., R. Thompson, J. Grams, C. Broyles, and H. Brooks, 2012: Convective modes for significant severe thunderstorms in the contiguous United States. Part I: Storm classification and climatology. Wea. Forecasting, 27, 1114-1135, https:// doi.org/10.1175/WAF-D-11-00115.1.

Stokoe, R., 2016: Putting people at the centre of tornado warnings: How perception analysis can cut fatalities. Int. J. Disaster Risk Reduct., 17, 137-153, https://doi.org/10.1016/j.ijdrr.2016.04.004.

Strader, S., and W. Ashley, 2018: Finescale assessment of mobile home tornado vulnerability in the central and southeast United States. Wea. Climate Soc., 10, 797-812, https://doi.org/ 10.1175/WCAS-D-18-0060.1.

, T. Pingel, and A. Krmenec, 2017a: Observed and projected changes in U.S. tornado exposure. Wea. Climate Soc., 9 , 109-123, https://doi.org/10.1175/WCAS-D-16-0041.1.

,,,--- and $-2017 \mathrm{~b}$ : Projected 21 st century changes in tornado exposure, risk, and disaster potential. Climatic Change, 141, 301-313, https://doi.org/10.1007/s10584-017-1905-4. , K. Ash, E. Wagner, and C. Sherrod, 2019: Mobile home resident evacuation vulnerability and emergency medical service access during tornado events in the Southeast United States. Int. J. Disaster Risk Reduct., 38, 101210, https://doi.org/ 10.1016/j.ijdrr.2019.101210.

Sutter, D., and K. Simmons, 2010: Tornado fatalities and mobile homes in the United States. Nat. Hazards, 53, 125-137, https:// doi.org/10.1007/s11069-009-9416-x.

Thompson, R., R. Edwards, J. Hart, K. Elmore, and P. Markowski, 2003: Close proximity soundings within supercell environments obtained from the Rapid Update Cycle. Wea. Forecasting, 18, 1243-1261, https://doi.org/10.1175/1520-0434(2003)018<1243: CPSWSE $>2.0 . \mathrm{CO} ; 2$.

— B. Smith, J. Grams, A. Dean, and C. Broyles, 2012: Convective modes for significant severe thunderstorms in the contiguous United States. Part II: Supercells and QLCS tornado environments. Wea. Forecasting, 27, 1136-1154, https:// doi.org/10.1175/WAF-D-11-00116.1.

Wakimoto, R., H. Murphey, E. Browell, and S. Ismail, 2006: The "triple point" on 24 May 2002 during IHOP. Part I: Airborne Doppler and LASE analyses of the frontal boundaries and convection initiation. Mon. Wea. Rev., 134, 231-250, https:// doi.org/10.1175/MWR3066.1. 